\title{
A clinical audit report on quality of nursing documentation at Jigme Dorji Wangchuck National Referral Hospital, 2018
}

\author{
Kencho Zangmo ${ }^{1}$, Tshering Dema ${ }^{2}$, Bhagawat Acharya ${ }^{3}$, Sonam ${ }^{4}$, Tshering Choden ${ }^{5}$, Kelzang Dechen ${ }^{6}$, Kinga Om
}

${ }^{1-7}$ Department of Nursing Administration and Services, Jigme Dorji Wangchuck National Referral Hospital, Thimphu, Bhutan

\begin{abstract}
Introduction: Whether it is a written documentation or an oral communication, the practice and delivery of healthcare is debated to be critically dependent on effective and efficient communication. Nursing documentation is one of the principal sources of information about patient care and an important tool for communication. This descriptive study assessed both quantitative completeness and quality of nursing documentation by major in-patient units of Jigme Dorji Wangchuck National Referral Hospital. Methods: This cross-sectional study used D-catch tool. Data of randomly selected 317 patient records from six major in-patient units were entered into EpiData file. Using STATA version IC/14, descriptive statistics and multi variable analysis were carried out. Results: Overall quantitative completeness $(M-3.4, S D-.59)$ of the nursing documentation was higher compared to the quality of the documents maintained $(M-2.8, S D-.79)$. The basic and less time-consuming information such as admission data and vital signs charting are documented better compared to the more time consuming and complex documentation such as nursing care process. Conclusions: Systems should not only be in place to enhance documentation quantitatively but also consider uplifting the quality of the documents maintained. Initiating centralized admission system in the hospital may reduce nurses' burden of clerical documentation, which will allow them to focus on quality nursing documentation and overall nursing care of patients.
\end{abstract}

Keywords: Medication record; Nursing assessment; Nursing care process; Nursing documentation.

\section{INTRODUCTION}

With the evolution of healthcare, there is increasing number of patients, especially with chronic illness requiring care by multidisciplinary health care team. The practice and delivery of healthcare is debated to be critically dependent on effective and efficient communication ${ }^{1,2}$. Information sharing and communication, whether oral or written, among healthcare team is an essential component to overall patient care. However, written communication remains the most prevalent form of communication. Breakdown in communication systems in health facilities and among healthcare givers is said to have large impact on patient safety ${ }^{3}$. The consequences of poor communication among healthcare givers includes: (1) discontinuity of care; (2) delays in treatment and diagnosis; (3) longer hospital stay and readmissions; (4) inappropriate treatment and omission of care; (5) patient dissatisfaction; and (6) inefficient use of valuable resources ${ }^{2,3,4}$.

\section{Corresponding author:}

Kencho Zangmo

kenchozangmo84@gmail.com
In addition to being one of the main functions of nurse, nursing documentation is also one of the principal sources of information about the patient care; hence, a major tool for communication among healthcare team ${ }^{5,6,7}$. Borsato and colleagues (2011) in the study assessing quality of nursing documentation stated that, nursing team provided $50 \%$ of the patient care information ${ }^{8}$. Nursing documentation as defined by Johnson and colleagues" states, "the nursing and midwifery documentation is a process in which the patient's experience from admission to discharge is recorded in a manner which enables all clinical staff involved in the patient's care to detect changes in the patient's condition and the patient's response to treatment and care delivery". In addition to being major tool of communication, nursing documents maintained in effective, accurate, and dynamic manner also serve as a reliable source for medico-legal purposes, quality assurance activities, health planning, resource allocation, and research activities ${ }^{10}$.

A core to nursing documentation is nursing care process, which serves as a framework for organizing and documenting nursing care through application of systematized care process ${ }^{8,11}$. The nursing care process model involves assessment, planning, implementation, and evaluation of patient situations with the 
ultimate goal to commit in providing safe and ethical care. Current research findings suggest a positive correlation between nursing care plans and the patient outcomes including reduced hospital stay; madating more research in the quality of those documents ${ }^{12,13}$. Despite nursing documentation being critical to safe and effective patient care, it is often seen as not as important as hands on nursing care ${ }^{14}$. Furthermore, evidences suggest that maintaining nursing documentation is viewed as burdensome and even as distraction from direct patient care; hence, compromising the quality of those documents ${ }^{1,12}$.

Similarly, in Bhutan, nurses are required to document the care they provide to the patient in standard nursing care process. In addition, nurses are also required to do clerical admission documentation involving all that general information of the patients, which elsewhere in similar setting like ours, is done by a medical clerk at admission center. Moreover, in our healthcare system, the patient information is heavily dependent on manual writing and register records. Furthermore, nurses are burdened with time constraints, mismatches between staffing resource and workload, and lack of guidelines for completing documentation. Therefore, the quality of nursing documentation may be contentious and looking into the quality of nursing documentation might give some insights and guidance to strengthen this important tool of communication for safe and quality patient care. Thus, this study was aimed at assessing the quality of nursing documentation in major in-patient units of the national referral hospital.

\section{METHODS}

\section{Study design and setting}

This descriptive study used data available at the medical record section of the Jigme Dorji Wangchuck National Referral Hospital. A study population of 1789 subjects were obtained from patient records from six major in-patient units (medical, surgical, maternity, orthopedic, pediatric, and cabin) of JDWNRH between October and December, 2018. Sample size of 317 patient files was calculated using online software called 'Raosoft' available at http://www.raosoft.com/samplesize.html. The sample representation from each in-patient unit was based on the patient turnover of that unit per month and sampling was done using simple random sampling method.

\section{Ethical consideration}

Prior to data collection, ethical approval for this study and waiver for informed consent was sought from the Research Ethics Board of Health, Ministry of Health, Bhutan (REBH/ Approval/2018/103). Administrative clearance for the study was sought from both Ministry of Health and the study site. All data collected are kept confidential and under no circumstances identifying characteristics of the participants were included in the study report.

\section{Data collection}

The study instrument has two major parts. The first part consists of general information from the patient file. The second part is the D-Catch instrument, which was developed by Prof. Wolter Paans ${ }^{15}$ and it is available for scientific use. The D-Catch is an instrument used to assess both quantity and quality of the nursing documentation, with an internal consistency (Cronbach's Alpha) of 0.72 and inter-rater reliability $\left(\mathrm{K}_{\mathrm{w}}\right)$ between 0.74 and 0.89. The D-Catch questionnaire is designed to measure both the completeness and quality of nursing documents, mainly the nursing assessment and nursing care processes documented. The questionnaire has six items, item one and six are single questions to measure quantitative completeness of overall nursing record (including admission data, vital signs chart, medication records, nursing assessment data, and nursing care process documented) and medication record legibility respectively. The other items (2-5) has two parts, each measuring quantity and quality of nursing assessment and care processes documented. The item for quantity assessment is rated as 1 (none) to 4 (complete) and the quality assessments is rated as 1 (poor) to 4 (very good). Although this study used D-Catch instrument in its original form, a slight alteration of terms based on our system of record keeping was done. Data collection used D-catch questionnaire guideline for scoring quantitative and qualitative assessments. Initially, the scoring was done by two individuals for all 317 patient files and a final score was taken as an average of the two scores.

\section{Data analysis}

Data were double entered into EpiData file and validated. Data were cleaned, coded, and analyzed using STATA version IC/ 14 (licensed to Khesar Gyalpo university of Medical Sciences of Bhutan). Descriptive commands such as frequency, percentage, mean, and standard deviations were used.

\section{RESULTS}

\section{Sample description}

A total 317 patient files from six major in-patient units were reviewed for assessment of completeness and quality of nursing documents. From the files reviewed, an average length of hospital stay was 6.3 days $(S D-9.9)$ with a minimum stay of zero days ( $<24$ hours) to as long as 122 days. While 134 of the patients were admitted for medical management including short stay observations, monitoring, investigation, and conservative management; 140 of the patients were admitted for various surgical procedures and 40 of the cases were for induction of labor and delivery.

\section{Quantitative completeness of nursing documentation}

Out of the six components of nursing documentation assessed based on D-catch tool, the legibility of medication record scored highest for completeness followed by nursing diagnosis documented. Overall, $49.8 \%$ of the structure of nursing record 
Table 1. Completeness of the overall nursing record structure

\begin{tabular}{lcccccccc}
\hline Completeness & Unit & Unit & Unit & Unit & Unit & Unit & Overall & $\boldsymbol{M}(\boldsymbol{S D})$ \\
\hline Incomplete & $\mathbf{1}$ & $\mathbf{2}$ & $\mathbf{3}$ & $\mathbf{4}$ & $\mathbf{5}$ & $\mathbf{6}$ & $\boldsymbol{N}(\mathbf{\%})$ & $16(5.0)$ \\
Partially complete & 2 & 12 & 1 & 0 & 0 & 1 & $3.4(0.59)$ \\
Complete & 12 & 48 & 23 & 6 & 41 & 13 & $143(45.1)$ \\
Missing records & 14 & 16 & 51 & 34 & 10 & 33 & $158(49.9)$ & \\
Nursing assessment & 1 & 4 & 1 & 0 & 0 & 0 & $6(1.9)$ & $157(49.5)$ \\
Nursing care process & 14 & 60 & 23 & 6 & 43 & 11 & $15(4.7)$ \\
Medication record & 4 & 5 & 0 & 0 & 3 & 3 &
\end{tabular}

Unit 1-6: these are different in-patient units that participated in the study

Table 2. Overal1 D-catch score for completeness (quantity) of nursing documentation

\begin{tabular}{lccccccc}
\hline Elements of D-catch & Scale & $\mathbf{M}(\mathbf{S D})$ & $\boldsymbol{N}$ & $\begin{array}{c}\text { Score 4 } \\
\boldsymbol{n}(\mathbf{\%})\end{array}$ & $\begin{array}{c}\text { Score 3 } \\
\boldsymbol{n}(\mathbf{\%})\end{array}$ & $\begin{array}{c}\text { Score 2 } \\
\boldsymbol{n}(\mathbf{\%})\end{array}$ & $\begin{array}{c}\text { Score 1 } \\
\boldsymbol{n}(\mathbf{\%})\end{array}$ \\
\hline $\begin{array}{l}\text { Nursing record structure } \\
\text { Admission record/nursing }\end{array}$ & $1-4$ & $3.45(.59)$ & 317 & $158(49.8)$ & $143(45.1)$ & $16(5.1)$ & 0 \\
$\begin{array}{l}\text { assessment form } \\
\text { Nursing diagnosis }\end{array}$ & $1-4$ & $3.25(.79)$ & 317 & $140(44.2)$ & $127(40.1)$ & $40(12.6)$ & $10(3.1)$ \\
$\begin{array}{l}\text { Nursing intervention } \\
\text { Nursing outcome evaluation }\end{array}$ & $1-4$ & $3.27(.91)$ & 160 & $85(53.1)$ & $43(26.9)$ & $23(14.4)$ & $9(5.6)$ \\
$\begin{array}{l}\text { Legibility of the medication } \\
\text { record }\end{array}$ & $1-4$ & $3.18(.82)$ & 160 & $68(42.5)$ & $58(36.5)$ & $30(18.7)$ & $4(2.5)$ \\
Quantity: $1=$ none, 2=incomplete, 3=partially complete, 4=complete & $2.85(.94)$ & 160 & $41(25.6)$ & $74(46.3)$ & $25(15.6)$ & $20(12.5)$ \\
\end{tabular}

Table 3. The D-catch score for quality of nursing care process documentation

\begin{tabular}{llllllll}
\hline \multicolumn{1}{c}{ Elements of D-catch } & Scale & $\mathbf{M}(\mathbf{S D})$ & $\mathbf{N}$ & $\begin{array}{r}\text { Score 4 } \\
\mathbf{n}(\mathbf{\%})\end{array}$ & $\begin{array}{r}\text { Score 3 } \\
\mathbf{n}(\mathbf{\%})\end{array}$ & $\begin{array}{c}\text { Score 2 } \\
\mathbf{n}(\mathbf{\%})\end{array}$ & $\begin{array}{c}\text { Score 1 } \\
\mathbf{n}(\mathbf{\%})\end{array}$ \\
\hline $\begin{array}{l}\text { Admission record/nursing } \\
\text { assessment form }\end{array}$ & $1-4$ & $2.78(.80)$ & 313 & $59(18.8)$ & $143(45.7)$ & $95(30.4)$ & $16(5.1)$ \\
Nursing diagnosis & $1-4$ & $2.68(.90)$ & 160 & $32(20.0)$ & $62(38.7)$ & $50(31.3)$ & $16(10.0)$ \\
Nursing intervention & $1-4$ & $2.53(.86)$ & 160 & $24(15.0)$ & $52(32.5)$ & $69(43.1)$ & $15(9.4)$ \\
Nursing outcome evaluation & $1-4$ & $2.27(.88)$ & 160 & $13(8.1)$ & $52(32.5)$ & $61(38.1)$ & $34(21.3)$ \\
\hline
\end{tabular}

Quality: $1=$ poor, $2=$ moderate, $3=$ good, $4=$ very good 
was complete, $45.1 \%$ partially complete, and $5.1 \%$ incomplete (see table 1). All 317 records had admission data and vital signs chart. However, of the 317 records, $48.9 \%$ of records did not have nursing care process while $4.7 \%$ and $1.9 \%$ did not have medication record and nursing assessment form respectively. An assessment of completeness of nursing documentation using D-catch tool showed a mean of 3.2 to 3.5 on a scale of 1 to 4 rating for all other components of document except for outcome evaluation of the nursing care process, which showed a rating of 2.8 (see table 2).

\section{Quality of nursing documentation}

Assessment of quality of nursing documentation using D-catch assessed only the quality of nursing assessment and nursing care process. The quality of nursing assessment was of moderate quality $(M-2.78, S D-0.80)$. The quality scores of the items measuring nursing care process, on average ranged from $2.2(S D)$ to $2.8(S D)$ on a scale of 1 to 4 rating (table 3 ). The overall quality of nursing care process showed that, $50 \%$ of nursing care process documentation are of good quality, $26.3 \%$ with moderate quality, $18.8 \%$ with very good quality, and $5 \%$ with poor quality.

\section{DISCUSSION}

The findings of this study suggest that overall quantitative completeness (M-3.4, SD-.59) of the nursing documentation is higher compared to the quality of the documents maintained $(M-2.8, S D-.79)$. The higher rating for quantitative assessment might have resulted from past clinical audit recommendations and policy changes put in place to uplift nursing assessment and care process documentation. However, the overall quality of the documentation rated at the level of moderate quality may require an in-depth investigation to explore the ways improve it. This finding is in line with the current literatures from other parts of the world suggesting that maintaining documentation is often seen as not as important as hands on nursing care and is viewed as burdensome and even as a distraction from direct patient care, hence the lacking in doing so ${ }^{1,12,14}$. This may be true in our setting too as indicated by the study results due to the additional burden our nurses have of clerical documentations in addition to nursing documentation. In addition, assessment into the overall structure of the nursing records showed that, while all 317 patient files had admission data and vital signs' chart, only 160 files had nursing care process chart, 302 had medication record, and 311 had nursing assessment form. This result of the overall structure of record may be interpreted that the basic, vital, and less time consuming information such as admission data, personal details of the patient, vital signs charting, and medication record are documented better compared to the more time consuming and complex documentation such as nursing care process. Our findings are in line with a similar study from Norway ${ }^{4}$.

The overall nursing assessment quantitative completeness $(M-3.25, S D-.79)$ was rated higher than the quality $(M-2.78, S D-.80)$ of the assessment documented. The quantitative investigation of nursing assessment showed majority of assessment document rated for complete (44.2\%) and partially complete $(40.1 \%)$ versus $15.7 \%$ rated for incomplete and not done. Some of the common components missing from nursing assessment documentation, contributing to partial completeness or incompleteness include: (1) reason for admission; (2) hospital registration number; (3) medical diagnosis; (4) discharge instruction; and (6) dated name and sign of the nurse doing the assessment. Therefore, even a missing hospital registration number or a nurse not signing the assessment form after documenting the assessment, had led to partial completeness or incompleteness. Our findings were slightly different from a review article on quality of nursing documentation, which stated that the common incomplete components of nursing assessment were psychosocial, spiritual, and previous health behavior ${ }^{13}$. However, both our study and the previous study showed inadequacies in patient discharge instruction and health education component of nursing assessment ${ }^{13}$. Considering the quality of nursing assessment documentation, majority of the documents fell under good and moderate quality scale compared to lesser documents rated on two extremes of very good and very poor quality. In addition, while nurses did all important assessments such as systemic assessment, they missed out on filling patient identifiers, vital signs, and reason for admission and one reason for this could be that this information being repeatedly documented in so many other documents. A critical finding that surfaced was, although nurses did nursing assessment on admission, lesser of those admission assessments were re-visited for continued health education and discharge instructions, which are both a mandate and critical to ensuring continued nursing care.

Nursing care process, quantitatively, was the least documented among five components of the overall structure of the nursing record that were investigated in this study. This finding may be interpreted that nursing care was not fully expressed in the records and anything that is not documented may be equated to not being done in practice as well ${ }^{13}$. According to the D-catch ${ }^{15}$ tool, nursing care process quality assessment has three components: nursing diagnosis which includes a diagnosis formed based on assessment data and a goal planning done in line with diagnosed issue; nursing intervention, and outcome evaluation. Investigating further into the quality of components of nursing care process, although all three components were rated at moderate quality, nursing diagnosis was rated best $(M-2.68$, $S D$ - .90) among the three with outcome evaluation rating least ( $M$ $-2.27, S D-.88)$. Based on these findings, it may be interpreted that nurses were formulating standard nursing diagnosis based on their assessment data and in line with their set goals followed by providing planned interventions. However, as the nursing care process documentation steps moved forward, the documentation quality lessened as the quality of nursing intervention documented was slightly lesser than diagnosis and outcome evaluation rated lesser than both the preceding steps. In addition, although nursing 
care process documentation is initiated by documenting initial steps of care process, there was lack of continuity of process as the care process that was begun was not been re-visited for outcome evaluation or outcome evaluation is not done in standard form. This finding is in line with international literature ${ }^{4,13}$ in terms of quality outcome evaluation documentation; however, the quality of nursing intervention and formulating diagnosis was rated comparatively higher in this study.

\section{CONCLUSIONS}

Overall, the quantitative completeness of nursing documentation was better compared to the quality of those documents maintained. Systems should be put in place to not only enhance documentation quantitatively but also consider uplifting quality of documents maintained. Proper audit tools for both quantitative and qualitative assessments should be developed or adopted to ensure a standard nursing care processes. Admission procedure should be centralized so that the burden of clerical documentation is lifted from nurses in order for them to focus on quality nursing documentation, that is internationally accepted and ultimately, ensuring continued quality nursing care.

\section{STUDY LIMITATIONS}

Although D-Catch tool scoring guide was used for data collection, the quality scoring might have been affected due subjective views and opinions of the data collector, which the study addressed through double independent assessment followed by common consensus scoring.

\section{ACKNOWLEDGEMENTS}

We would like to acknowledge the department of nursing administration and services of JDWNRH for logistic support and to medical record section staff in the hospital for their support in data extraction.

\section{REFERENCES}

1. American Nursing Association. ANA's Principles for Nursing Documentation: Guidance for Registered Nurses. 2010. [Full Text]

2. Vermeir P, Vandijck D, Degroote S, Peleman R, Verhaeghe $\mathrm{R}$, Mortier E, et al. Communication in healthcare: a narrative review of the literature and practical recommendations. The International Journal of Clinical Practice. 2015;69(11):125767. [Full Text | DOI]

3. King B, Gilmore-Bykovskyi A, Roiland R, Polnaszek B, Bowers B, Kind A. The consequences of poor communication during transitions from hospital to skilled nursing facility: A Qualitative Study. Journal of The American Geriatrics Society. 2013;61(7):1095-102. [Full Text | DOI]
4. Instefjord $\mathrm{MH}$, Aasekjaer K, Espehaug B, Graverholt B. Assessment of quality in psychiatric nursing documentation - a clinical audit. BM C Nursing. 2014;13(32). [Full Text | DOI]

5. Hector DS. Retrospective analysis of nursing documentation in the intensive care units of an academic hospital in the western Cape. Thesis presented in partial fulfilment of the degree of Magister Curations (Nursing) at the Stellenbosch University.2010:78-87. [Full Text]

6. Lindo J, Stennett R, Stephenson-Wilson K, Barrett KA, Bunnaman D, Anderson-Johnson P, et al. An audit of nursing documentation at three public hospitals in Jamaica. Journal of Nursing Scholarship.2016;48(5):499-507. [Full Text | DOI]

7. Tornvall E. Nursing documentation for communicating and evaluating care. Journal of Clinical Nursing. 2008:17(16): 2116-24. [Full Text | DOI]

8. Borsato FG, Rossaneis MA, Carmo M, Haddad FL, Vannuchi, MTO, Vituri, DW. Assessment of quality of nursing documentation in a University Hospital. Acta Paul Enferm. 2011;24(4):521-33. [DOI]

9. Johnson M, Jefferies D, Langdon R. The nursing and midwifery content audit tool (NMCAT): a short nursing documentation audit tool. Journal of Nursing Management. 2010;(18):832-45. [Full Text | DOI]

10. Scruth EA. Quality nursing documentation in the medical record. Clinical Nurse Specialist. 2014; 28(6):312-4. [Full Text | DOI]

11. Mykkanen M, Saranto K, Miettinen M. Nursing audit as a method for developing nursing care and ensuring patient safety.2012. [Full Text]

12. Blair W, Smith B. Nursing documentation: frame works and barriers. Contemporary nurse: A Journal for the Australian Nursing Profession.2012;41(2):160-8. [Full Text | DOI]

13. Wang N, Hailey D, Yu P. Quality of nursing documentation and approaches to its evaluation: a mixed-method systematic review. Journal of Advanced Nursing. 2011; 67(9): 1858-75. [Full Text | DOI]

14. Hoban V. How to improve your record keeping. Nursing Times.2003;99(42):78-9.

15. Paans W, Sermeus W, Nieweg RMB, van der Schans CP. D-Catch instrument: development and psychometric testing of a measurement instrument for nursing documentation in hospitals. Journal of Advanced Nursing.2010;66(6):1388-400. [Full Text | DOI] 


\section{AUTHORS CONTRIBUTION}

Following authors have made substantial contributions to the manuscript as under:

KZ: Concept, design, data collection and analysis, manuscript writing and review.

TD: Design, data collection and analysis, manuscript writing and review

BA: Design, data collection and analysis, manuscript writing and review

S: Design, data collection and analysis, manuscript writing and review

TC: Design, data collection and analysis, manuscript writing and review

KD: Design, data collection and analysis, manuscript writing and review

KO: Design, data collection and analysis, manuscript writing and review

Author agree to be accountable for all respects of the work in ensuring that questions related to the accuracy and integrity of any part of the work are appropriately investigated and resolved.

\section{CONFLICT OF INTEREST}

None

GRANT SUPPORT AND FINANCIAL DISCLOSURE

Ministry of Health, Thimphu, Bhutan 